\title{
Alg Pigmentlerinin Tekstilde Doğal Boyar Madde Olarak Kullanımı
}

\author{
Elif BAYRAKTAR ${ }^{1}$, İnci TÜNEY KIZILKAYA ${ }^{* 1}$ \\ ${ }^{1}$ Ege Üniversitesi, Fen Fakültesi, Biyoloji Bölümü, 35100, İzmir
}

(Alınış / Received: 17.10.2017, Kabul / Accepted: 15.03.2018, Online Yayınlanma / Published Online: 16.04.2018)

\begin{abstract}
Anahtar Kelimeler
Alg,

Pigment,

Tekstil boyası,

Işık haslığı

Özet: Bu çalışmada, mikroalglerden Chlorella vulgaris Beyerinck (Beijerinck), Porphyridium cruentum (S.F.Gray) Nageli ve Haematococcus pluvialis Flotow ve makroalglerden Ulva lactuca Linnaeus ve Gracilaria gracilis (Stackhouse) M.Steentoft, L.M.Irvine \& W.F.Farnham türlerinden pigment ekstraksiyonu gerçekleștirilmiş ve elde edilen pigmentlerin tekstil sanayiinde doğal boyar madde olarak kullanımı konusunda verimliliği araştırılmıștır. Kulanılan türlerden üç farklı çözgen aracılığıyla pigment ekstraksiyonu gerçekleştirilmiş ve her ekstrakt için 4 farklı mordanlama kimyasalı kullanılmıştır. Boyama işleminde yün iplikten faydalanılmıştır. Boyanan iplikler ışık haslığına göre değerlendirilmiștir. İplik boyamada en etkili olan türlerin U. lactuca ve G. gracilis olduğu tespit edilmiștir. En iyi mordanlama ise $\mathrm{CuSO}_{4}, \mathrm{FeSO}_{4}$ kimyasalları ile gerçekleştirilmiştir.
\end{abstract}

\section{Pigment Extraction From Algae and Usage as Natural Textile Dye}

\section{Keywords \\ Algae, \\ Pigment, \\ Textile dye, \\ Fastness}

\begin{abstract}
In this study we studied the performance of the algal pigments as textile dye. The pigments of Ulva lactuca Linnaeus, Gracilaria gracilis (Stackhouse) M.Steentoft, L.M.Irvine \& W.F.Farnham, Chlorella vulgaris Beyerinck (Beijerinck), Porphyridium cruentum (S.F.Gray) Nageli and Haematococcus pluvialis Flotow were extracted. Three different solutions used for pigment analysis from all micro and macro algae. Four different chemicals used for coloring procedure. Woolen threads used for the coloring process. Light resistance analysis was performed to dyed threads. The best fastness result obtained from macroalgae $U$. lactuca and $G$. gracilis. The best coloring chemicals were determined as $\mathrm{CuSO}_{4}, \mathrm{FeSO}_{4}$.
\end{abstract}

\section{Giriş}

Günümüzde ticari olarak 100.000 çeşit boya bulunmakta ve bu miktarın da \%50'si tekstil alanında kullanılmaktadır [1, 2]. Dünyada yıllık 21 milyon tona yakın pamuğun renklendirilmesinde 120.000 ton reaktif boyar madde tüketilmektedir $[3,4]$. Boyar madde olarak kullanılan maddelerin belirli kriterlere sahip olması beklenmektedir. Bunlar; gölge derinliği, boyanın kromotografik gücü, tonların parlaklığı gibi parametrelerdir [2]. Her ne kadar günümüzde çevreye zararsız olan malzemelerin kullanımı yaygınlaşmış olsa da çoğu materyalin dayanıklı ve kimyasallarla çözünmeyen özellikte olması istenmektedir. Bu özellikler ise tekstil boyama endüstrisi atık sularında belirli miktarda boya ve kimyasalın bulunmasına yol açmaktadır. Diğer bir taraftan çevre sorunlarına karşı gelişen farkındalık ve endişeler, endüstriyel atıkların azaltılması, yeniden kullanımı ya da doğada çözünebilir olmasını zorunlu hale getirmektedir [2]. Tekstil boyama ünitelerinin atıklarının arıtımı renk yoğunluğu ve kompozisyon çeşitliliği dolayısıyla çok tatmin edici sonuçlar vermemektedir. Üretilen boyaların yaklaşık \%2'sinin doğrudan sucul ortama deşarj edildiği ve \%10'unun boyama işlemleri sırasında kaybolduğu tahmin edilmektedir [5].

Dünya genelinde kullanılan renklendiricilerin büyük bir kısmını azo boyalar olușturmaktadır. Bu bileşiklerin atıksularda bulunması, sucul ekosistemler ve insan sağlığı için toksik etkilere sebebiyet verebilmektedir [6]. Bu nedenle doğal boyar maddeler tekstil endüstrisinde güvenli bir alternatif oluşturmaktadır. Renklendirici kaynağı olarak ise bitkiler, algler ve bakteriler umut vadeden organizmalardır.

Algler birçok biyoteknolojik ve endüstriyel alanda kullanılan önemli bir doğal kaynaktır. İçerdikleri biyoaktif bileşiklerin etkileri tıp, eczacılık gibi alanlarda yoğun olarak çalışılmakta ve kullanım alanları yaygınlaşmaktadır [7]. Alglerden elde edilen önemli maddelerden biri de pigmentlerdir. Algler, 
klorofiller, karotenoidler ve fikobilinler olmak üzere 3 ana pigment grubunu içermektedirler. Klorofiller yeşilimsi renkte ve porfirin halkası içeren pigmentlerdir. Birçok çeşidi bulunsa da en önemlisi, fotosentezin anahtarı klorofil a pigmentidir. Bunun dışında yeşil algler ve bitkilerde klorofil b, Chromista ve Dinopyta gruplarinda klorofil c bulunur. Karotenoidler ise genellikle kırmızımsı-turuncu renklidir. Bu bileşikler, birbirine karbon zinciriyle bağlı iki küçük 6 karbonlu halkadan oluşmuştur. Suda çözünmezler. Güneş enerjisinden gelen enerjiyi doğrudan fotosentetik yolağa sokamazlar ancak absorbe ettikleri enerjiyi klorofile aktarırlar. Bu nedenle de yardımcı pigment olarak adlandırılırlar. Fikobilinler, suda çözünebilen pigmentlerdir. Genellikle siyanobakteriler ve kırmızı alglerde bulunurlar.

Çalışmamızda Urla (İzmir) kıyılarından toplanan 2 makroalg ve E.Ü Biyoloji Bölümü, Hidrobiyoloji Araştırma Laboratuvarında kültüre alarak ürettiğimiz 3 mikroalg türünden pigment izolasyonu gerçekleştirilerek iplik boyamadaki kullanılabilirliği araştırılmıştır.

\section{Materyal ve Metot}

\subsection{Alg materyali}

$\mathrm{Bu}$ çalışmada Urla (İzmir) kıyılarından toplanan $U$. lactuca ve G. gracilis makroalgleri ile Ege Üniversitesi Mikroalg Kültür Koleksiyonu (EGEMACC)'ndan stok kültürü temin edilen $C$. vulgaris, $H$. pluvialis ve $P$. cruentum mikroalgleri kullanılmıștır. P. cruentum türü Blue-Green 11 (BG11), H. pluvialis ve $C$. vulgaris türleri ise Bold Basal Medium (BBM) besi ortamı içerisinde laboratuvar ortamında çoğaltılmışlardır. Mikroalg üretimi aşamasında laboratuvar sıcaklığı $20^{\circ} \mathrm{C}^{\prime}$ ye ayarlanmış ve $8 \mathrm{sa} / 16 \mathrm{sa}$ aydınlık/karanlık döngüsünde yetiştirme işlemi gerçekleştirilmiştir.

\subsection{Pigment ekstraksiyonu}

Santrifüj yöntemiyle yoğunlaștırılan ve besi ortamı uzaklaştırılan mikroalg türlerinden elde edilen pasta kıvamındaki biyokütle tepsiye yayılarak $40^{\circ} \mathrm{C}$ 'de etüvde, biyomasın kalınlığına bağlı olarak 3-6 saat arasında kurutma işlemine maruz bırakılmıştır.

Laboratuvar ortamina getirilerek temizlenip epifitlerinden ayrılan makroalg türleri ise tepsilere serilen kurutma kağıtlarının üzerine ince katmanlar halinde dizilmiştir. Ardından $40^{\circ} \mathrm{C}^{\prime}$ lik bir etüvde 5-6 saat süreyle kurutma işlemine maruz bırakılmıştır.

Tamamen kurumuş halde etüvden çlkarılan örnekler geniş bir havan içerisine alınarak havan eli yardımıyla ve sıvı azot eklenerek dövülmüș ve hücre duvarının mekanik olarak parçalanması sağlanmıştır.
Ögütme işleminin ardından her türden 20'şer gramlık 12 adet grup oluşturulmuştur. 12 grup ise 3 farklı çözgen (\%70 Etanol, \%60 Metanol ve \%99,9 Metanol) ile ekstraksiyona tabi tutulmuştur (Şekil 1). $\mathrm{Bu}$ gruplar belirtilen farklı çözgenler ile birlikte 250 mL'lik erlenler içerisine alınarak 5'er dakika ultrasonikatör içerisinde bekletilmiștir. Erlen içerisindeki örneklerin etrafi aluminyum folyo ile sarılarak 24 saat süresince belirli aralıklarla çalkalanarak inkübe edilmiştir.

Örneklerdeki pigment miktarı spektrofotometrik yöntemlerle belirlenmiștir. Toz haline getirilen alg materyalinden toplam karotenoid pigmentlerinin tayini için Sumanta vd. [8], Torres vd. [9] ve Dere vd. [10]'nin yöntemleri modifiye edilerek kullanılmıştır. Modifiye edilen yöntem aşağıdaki basamaklar halinde gerçekleştirilmiştir.

Her 1 gram toz halindeki örnek için $10 \mathrm{~mL} \% 80$ aseton cam tüplere eklenmiş ve $65^{\circ} \mathrm{C}$ su banyosunda 30 dakika inkübe edilmiştir. İnkübasyonun ardından 15 dakika 5.000 rpm'de santrifüj işlemi gerçekleștirilmiş ve sıvı faz yeni bir tüpe aktarılmıştır.

Yeni tüpe aktarılan üst fazdan alınarak bir eppendorf tüpe aktarılıp, üzerine \%80'lik aseton eklenmiş ve $470 \mathrm{~nm}$ dalgaboyunda 3 tekrarlı olacak şekilde spektrofotometre cihazında (Pharo 300, Merck) ölçülmüştür. Hesaplamalar için aşağıdaki formül kullanılmıştır:

Toplam karotenoid $=\left(1000 \mathrm{~A}_{470}-1.82 \mathrm{C}_{\mathrm{a}}-85.02 \mathrm{C}_{\mathrm{b}}\right) / 198$

\section{3. İplik boyama}

Her çözgen ekstraktı için farklı mordanlama yapılmıştır (Şekil 1). Mordanlama işlemi için, şap $\left(\mathrm{KAl}\left(\mathrm{SO}_{4}\right)_{2} \cdot 12 \mathrm{H}_{2} \mathrm{O}\right)$, demir (II) sülfat $\left(\mathrm{FeSO}_{4}\right)$, magnezyum klorid $\left(\mathrm{MgCl}_{2}\right)$ ve bakır (II) sülfat $\left(\mathrm{CuSO}_{4}\right)$ kimyasalları kullanılmıştır.

Elde edilen toz halindeki pigmentler $200 \mathrm{~mL}$ distile suda çözülerek üzerlerine 0,1 g mordan kimyasalı eklenmiştir. Ardından boyayı daha iyi çekmesi için 30 g iplik $200 \mathrm{~mL}$ distile suda (1:6 banyo oranı) 1 saat sslatılmıştır. Sonrasında sıcaklığ $90^{\circ} \mathrm{C}$ 'ye çıkarılan su banyosu içerisinde sicaklık sabit tutularak ipler 40 dakika kadar boyanmaya devam edilmiștir (Şekil 2). $\mathrm{Bu}$ işlem sonunda pigment karışımı içerisindeki ipler bu sıvı ile birlikte soğumaya bırakılmış ve soğumanın ardından yine aynı sıvıda 24 saat süresince bekletilmiştir. 24 saat sonunda boyalı sudan çlkartılan iplikler önce akar vaziyetteki soğuk sudan, ardından yine akar vaziyetteki llık sudan geçirilerek durulanmış ve kurumaları için serilmiştir. Tüm gruplar için boyama işlemi mordansız olarak da gerçekleştirilmiştir. 

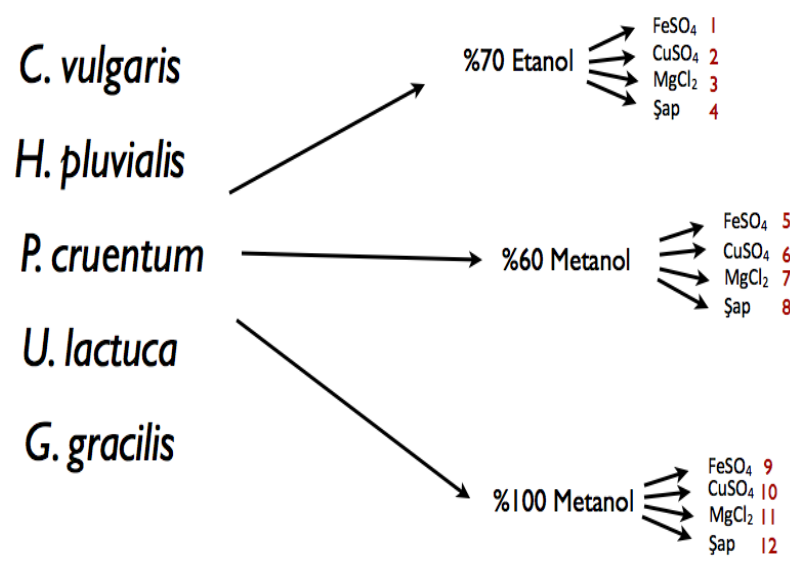

Şekil 1. Deneme için kullanılan alg grupları ve pigment ekstraksiyonunda kullanılan çözgenler

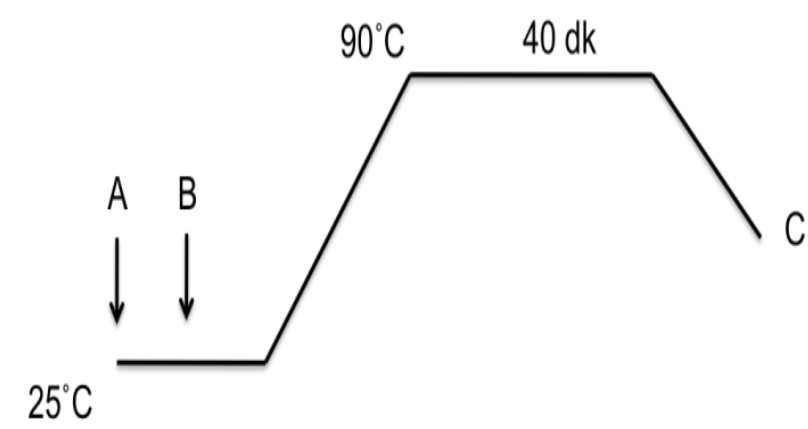

Şekil 2. Boyama diyagramı (A: Boya, B: Mordan, C: Yıkama)

\section{Bulgular}

Boyama ișleminde kulanılan pigmentlerin miktarı spektrofotometrik yöntemlerle belirlenmiştir. En yüksek pigent miktarı sirasıyla $P$. cruentum, $H$. pluvialis, C. vulgaris, U. lactuca ve G. gracilis olarak belirlenmiștir. G. gracilis'ten elde edilen toplam karotenoid miktarı oldukça düşük olup $0,002 \mu \mathrm{g} / \mathrm{mL}$, U. lactuca'dan elde edilen miktar ise $0,250 \mu \mathrm{g} / \mathrm{mL}$ 'dır. C. vulgaris $1,67 \mu \mathrm{g} / \mathrm{mL}, P$. cruentum'un $6,319 \mu \mathrm{g} / \mathrm{mL}$, H. pluvialis'in ise $1,836 \mu \mathrm{g} / \mathrm{mL}$ toplam karotenoid miktarına sahip olduğu tespit edilmiştir.

İplerin boyanması, durulanması ve kurutulması sonrasında hizmet alımı yoluyla tekstil laboratuvarında, ışık haslığı test cihazı içerisinde ISO 105 B02 normuna göre değerlendirme yapılmış ve mavi yün skalasında 5'e kadar soldurma gerçekleştirilmiştir (Şekil 3). Değerleri 1 ve 2 olan ipliklerin ışık haslığı sırasıyla çok az ve az, 3 olanlar orta, 4- iyi, 5- çok iyi olarak değerlendirilmektedir. Değeri 3 olan iplikler pigment maddelerini daha iyi tutmakla birlikte 4 ve 5 değerindekiler tekstil üretimi için değerli sınıfına girmektedirler. Tablo 1 ve 2'de boyama grupları ve haslık dereceleri görülmektedir.

Haslık dereceleri incelendiğinde en yüksek olarak 4/5 haslık derecesinin elde edildiği görülmüștür. 60 örneğin 20 tanesi bu haslık derecesine sahiptir. $\mathrm{Bu} 20$ ipliğin ortak özelliği $\mathrm{CuSO}_{4}$ ya da $\mathrm{FeSO}_{4}$ ile mordanlanmış olmalarıdır. En düşük haslık derecesi ise $\% 100$ metanol ile $C$. vulgaris'ten yapilan pigment ekstraskiyonu ve ardından şap ile mordanlanarak boyama sonucunca elde edilmiştir.

Haslık değeri başarısı türlere göre incelendiğinde en yüksek başarıyı $U$. lactuca ve $G$. gracilis makroalglerinden elde edilen pigmentlerle boyanan iplikler göstermiştir; haslık dereceleri 3 ile $4 / 5$ arasında değişmektedir. 3 ve üzeri haslık dereceleri tekstilde boya maddesi olarak kulanılabilecek kalitede olduklarını belirtmektedir. En düşük haslık sonucu ise $C$. vulgaris pigmenti ile yapilan boyamalarda elde edilmiştir. 12 örnekten 6'sı 3 ve üzeri sonuç vermiştir. İyi sonuç verenler ise $\mathrm{CuSO}_{4}$ ya da $\mathrm{FeSO}_{4}$ ile mordanlama yapılmış olan ipliklerdir.

Tüm ipliklerde mordanlama işlemi uygulanmıștır. Mordanlama işlemi için en yaygın kullanılan mordanlama kimyasallarından $\mathrm{CuSO}_{4}, \mathrm{FeSO}_{4}, \mathrm{MgCl}_{2}$ ve şap kullanılmıștır. $\mathrm{CuSO}_{4}$ ve $\mathrm{FeSO}_{4}$ ile mordanlama yapılan tüm iplikler $3 / 4$ ve üzeri sonuçlar vermiștir. $\mathrm{MgCl}_{2}$ ile mordanlama yapılan 15 grubun 9 tanesi 3 ve üzeri haslık değeri gösterirken şap ile mordanlamada başarılı grup sayısı 8'e inmiştir. Tüm boyama grupları için mordansız boyama işlemi de gerçekleştirilerek boyamaya etkisinin mordan maddelerinden $\mathrm{mi}$ yoksa alg pigmentinden $\mathrm{mi}$ kaynaklandığının tespiti hedeflenmiştir. Sonuç olarak mordansız boyanan ipliklere ait haslık değerleri Tablo 1'de gösterilmiştir.

Pigment ekstraksiyonundaki çözgenlerin etkisi karşılaştırıldığında ise önemli bir fark gözlenememiştir. Tüm alglerden $\% 70$ etanol, $\% 60$ metanol ve $\% 100$ metanol ile pigment ekstraksiyonu yapılmıştır. Bu ekstraksiyon sonucu elde edilen pigmenler iplik boyamada kullanıldığında çözgene bağlı bir fark olmadığı gözlenmiștir.

Tablo 1. Mordanlama yapılmadan sadece alg ekstraktları ile boyama işlemi yapılan ipliklerin haslık değerleri

\begin{tabular}{|c|l|c|}
\hline Alg Türü & Çözgen & Haslık Değeri \\
\hline \multirow{4}{*}{ C. vulgaris } & $\% 70$ etanol & 2 \\
\cline { 2 - 3 } & $\% 60$ metanol & $2 / 3$ \\
\cline { 2 - 3 } & $\% 100$ metanol & 1 \\
\hline \multirow{4}{*}{ H. pluvialis } & $\% 70$ etanol & $2 / 3$ \\
\cline { 2 - 3 } & $\% 60$ metanol & 3 \\
\cline { 2 - 3 } & $\% 100$ metanol & 3 \\
\hline \multirow{4}{*}{ cruentum } & $\% 70$ etanol & $2 / 3$ \\
\cline { 2 - 3 } & $\% 60$ metanol & $2 / 3$ \\
\cline { 2 - 3 } & $\% 100$ metanol & 3 \\
\hline \multirow{4}{*}{ G. gractuca } & $\% 70$ etanol & 4 \\
\cline { 2 - 3 } & $\% 60$ metanol & 3 \\
\cline { 2 - 3 } & $\% 100$ metanol & 4 \\
\hline & $\% 70$ etanol & $3 / 4$ \\
\cline { 2 - 3 } & $\% 60$ metanol & $3 / 4$ \\
\cline { 2 - 3 } & $\% 100$ metanol & 4 \\
\hline
\end{tabular}


Tablo 2. Boyanan ipliklerin ışık haslığı değerleri, boyamada kullanılan mordan kimyasalı ve boyamada kullanılan pigmentin ekstrakte edildiği çözgenler

\begin{tabular}{|c|c|c|c|c|}
\hline İplik \# & Alg Türü & Çözgen & Mordan & Işık Haslığı değeri \\
\hline 1 & C. vulgaris & $\% 70$ etanol & $\mathrm{FeSO}_{4}$ & $4 / 5$ \\
\hline 2 & C. vulgaris & $\% 70$ etanol & $\mathrm{CuSO}_{4}$ & $4 / 5$ \\
\hline 3 & C. vulgaris & $\% 70$ etanol & $\mathrm{MgCl}_{2}$ & 2 \\
\hline 4 & C. vulgaris & $\% 70$ etanol & Șap & 2 \\
\hline 5 & C. vulgaris & $\% 60$ metanol & $\mathrm{FeSO}_{4}$ & 4 \\
\hline 6 & C. vulgaris & $\% 60$ metanol & $\mathrm{CuSO}_{4}$ & $4 / 5$ \\
\hline 7 & C. vulgaris & $\% 60$ metanol & $\mathrm{MgCl}_{2}$ & $2 / 3$ \\
\hline 8 & C. vulgaris & $\% 60$ metanol & Șap & $2 / 3$ \\
\hline 9 & C. vulgaris & $\% 100$ metanol & $\mathrm{MgCl}_{2}$ & $1 / 2$ \\
\hline 10 & C. vulgaris & $\% 100$ metanol & Şap & 1 \\
\hline 11 & P. cruentum & $\% 70$ etanol & $\mathrm{FeSO}_{4}$ & $4 / 5$ \\
\hline 12 & P. cruentum & $\% 70$ etanol & $\mathrm{CuSO}_{4}$ & $4 / 5$ \\
\hline 13 & P. cruentum & $\% 70$ etanol & $\mathrm{MgCl}_{2}$ & $3 / 4$ \\
\hline 14 & P. cruentum & $\% 70$ etanol & Șap & $2 / 3$ \\
\hline 15 & P. cruentum & $\% 60$ metanol & $\mathrm{FeSO}_{4}$ & $4 / 5$ \\
\hline 16 & P. cruentum & $\% 60$ metanol & $\mathrm{CuSO}_{4}$ & $4 / 5$ \\
\hline 17 & P. cruentum & $\% 60$ metanol & Şap & $2 / 3$ \\
\hline 18 & P. cruentum & $\% 100$ metanol & $\mathrm{FeSO}_{4}$ & $3 / 4$ \\
\hline 19 & P. cruentum & $\% 100$ metanol & $\mathrm{CuSO}_{4}$ & 4 \\
\hline 20 & P. cruentum & $\% 100$ metanol & $\mathrm{MgCl}_{2}$ & 3 \\
\hline 21 & P. cruentum & $\% 100$ metanol & Şap & 3 \\
\hline 22 & H. pluvialis & $\% 70$ etanol & Şap & $2 / 3$ \\
\hline 23 & H. pluvialis & $\% 60$ metanol & $\mathrm{FeSO}_{4}$ & $4 / 5$ \\
\hline 24 & H. pluvialis & $\% 60$ metanol & $\mathrm{MgCl}_{2}$ & $2 / 3$ \\
\hline 25 & H. pluvialis & $\% 60$ metanol & Șap & 3 \\
\hline 26 & H. pluvialis & $\% 100$ metanol & $\mathrm{FeSO}_{4}$ & 4 \\
\hline 27 & H. pluvialis & \%100 metanol & $\mathrm{CuSO}_{4}$ & 3 \\
\hline 28 & H. pluvialis & $\% 100$ metanol & $\mathrm{MgCl}_{2}$ & 3 \\
\hline 29 & U. lactuca & $\% 70$ etanol & $\mathrm{FeSO}_{4}$ & $4 / 5$ \\
\hline 30 & U. lactuca & $\% 70$ etanol & $\mathrm{CuSO}_{4}$ & $4 / 5$ \\
\hline 31 & U. lactuca & $\% 70$ etanol & $\mathrm{MgCl}_{2}$ & $2 / 3$ \\
\hline 32 & U. lactuca & $\% 70$ etanol & Șap & 4 \\
\hline 33 & U. lactuca & $\% 60$ metanol & $\mathrm{FeSO}_{4}$ & $4 / 5$ \\
\hline 34 & U. lactuca & $\% 60$ metanol & $\mathrm{CuSO}_{4}$ & $4 / 5$ \\
\hline 35 & U. lactuca & $\% 60$ metanol & $\mathrm{MgCl}_{2}$ & 4 \\
\hline 36 & U. lactuca & $\% 60$ metanol & Şap & 4 \\
\hline 37 & U. lactuca & \%100 metanol & $\mathrm{FeSO}_{4}$ & 4 \\
\hline 38 & U. lactuca & $\% 100$ metanol & $\mathrm{CuSO}_{4}$ & $4 / 5$ \\
\hline 39 & U. lactuca & $\% 100$ metanol & $\mathrm{MgCl}_{2}$ & $3 / 4$ \\
\hline 40 & U. lactuca & \%100 metanol & Şap & 3 \\
\hline 41 & G. gracilis & $\% 70$ etanol & $\mathrm{FeSO}_{4}$ & $4 / 5$ \\
\hline 42 & G. gracilis & $\% 70$ etanol & $\mathrm{CuSO}_{4}$ & 4 \\
\hline 43 & G. gracilis & $\% 70$ etanol & $\mathrm{MgCl}_{2}$ & 4 \\
\hline 44 & G. gracilis & $\% 70$ etanol & Şap & 4 \\
\hline 45 & G. gracilis & \%60 metanol & $\mathrm{FeSO}_{4}$ & $4 / 5$ \\
\hline 46 & G. gracilis & $\% 60$ metanol & $\mathrm{CuSO}_{4}$ & $4 / 5$ \\
\hline 47 & G. gracilis & $\% 60$ metanol & Șap & $3 / 4$ \\
\hline 48 & G. gracilis & \%100 metanol & $\mathrm{FeSO}_{4}$ & $4 / 5$ \\
\hline 49 & G. gracilis & $\% 100$ metanol & $\mathrm{MgCl}_{2}$ & 4 \\
\hline 50 & G. gracilis & $\% 100$ metanol & Șap & 4 \\
\hline 51 & H. pluvialis & $\% 70$ etanol & $\mathrm{FeSO}_{4}$ & 4 \\
\hline 52 & H. pluvialis & $\% 70$ etanol & $\mathrm{CuSO}_{4}$ & $4 / 5$ \\
\hline 53 & H. pluvialis & $\% 70$ etanol & $\mathrm{MgCl}_{2}$ & 4 \\
\hline 54 & H. pluvialis & $\% 60$ metanol & $\mathrm{CuSO}_{4}$ & $4 / 5$ \\
\hline 55 & P. cruentum & \%60 metanol & $\mathrm{MgCl}_{2}$ & $2 / 3$ \\
\hline 56 & G. gracilis & $\% 60$ metanol & $\mathrm{MgCl}_{2}$ & 3 \\
\hline 57 & C. vulgaris & $\% 100$ metanol & $\mathrm{FeSO}_{4}$ & 4 \\
\hline 58 & C. vulgaris & \%100 metanol & $\mathrm{CuSO}_{4}$ & $4 / 5$ \\
\hline 59 & G. gracilis & $\% 100$ metanol & $\mathrm{CuSO}_{4}$ & 4 \\
\hline 60 & H. pluvialis & $\% 100$ metanol & Şap & $2 / 3$ \\
\hline
\end{tabular}




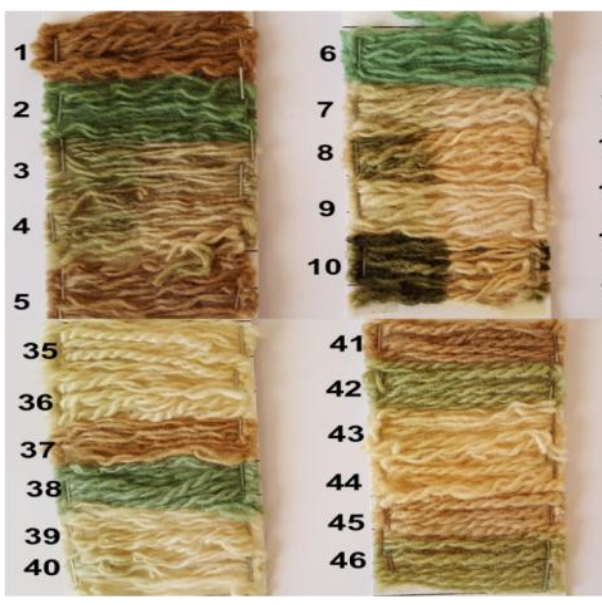

Şekil 3. Alg pigmentleriyle boyanan iplikler

\section{Tartışma ve Sonuç}

Doğal boyar maddelerin mağara resimlerinin çiziminde kullanımına ait veriler MÖ 15.000-9.000 yıllarına kadar dayanmaktadır [11]. Tekstilde bu maddelerin kulanımına ait veriler ise, klyafetlerin dayanıklılı̆̆ı düșük olduğu için, MÖ 3.200 yıllarına aittir. Tarihi verilere bakıldığında iklim şartlarına bağlı olarak değişkenlik gösteren birçok bitki doğal boyar madde kaynağı olarak kullanıldığı görülmektedir [12]. Çivit otu, kök boyası ve hanım tuzluğu bu bitkilerin başlıcalarıdır. Bitkiler, en eski çağlardan beri renklendirmede kullanılan zengin birer pigment kaynağı olmuşlardır. Algler de bitkiler gibi önemli bir pigment kaynağıdır, Sahip oldukları pigmentler ve diğer doğal maddeler sayesinde endüstriyel kullanımlarının yanında farmasötik ve nutrasötik olarak da yaygın olarak kullanılmaktadırlar [7]. Alglerden elde edilen pigmentler temel olarak 3 ana sinif altında toplanmaktadır: klorofil, karotenoid (karoten ve ksantofiller) ve fikobilinler [13]. Bu pigmentler belirli alg grupları için karakteristiktirler. Klorofil ve karotenler genellikle yağda çözünen moleküllerdir ve aseton, metanol, DMSO veya etanol gibi organik çözgenler yardımıyla ekstrakte edilebilmektedirler. Fikobilin ve peridinin ise suda çözünürler ve ancak algal dokulardan klorofilin organik çözücülerle uzaklaștırılması sonrasında yine aynı dokulardan elde edilebilmektedirler. Günümüzde alglerden elde edilen pigmentlerin özellikle kozmetikte ve gida renklendiricisi olarak geniş bir kullanım alanı bulunmaktadır [14].

19. yüzyılın sonlarına kadar doğal boyar maddeler tekstil sektörünün temel renklendiricileriydi. Ancak sentetik boya sektörünün 20. yüzyılın başlarından itibaren başlayan gelişimi doğal boyar maddelere alternatif oluşturmuştur. Sentetik boyar maddeler doğal olanlara oranla daha uzun ömürlü ve tekrarlanabilir oluşuyla yaygın olarak kullanılmaya başlanmıştır [15, 11]. Günümüzde çevreyi en çok kirleten endüstrilerden birinin tekstil endüstrisi olduğu bilinmektedir [16, 17]. Yılda 120.000 tona yakın reaktif boyar madde kullanıldığı tahmin

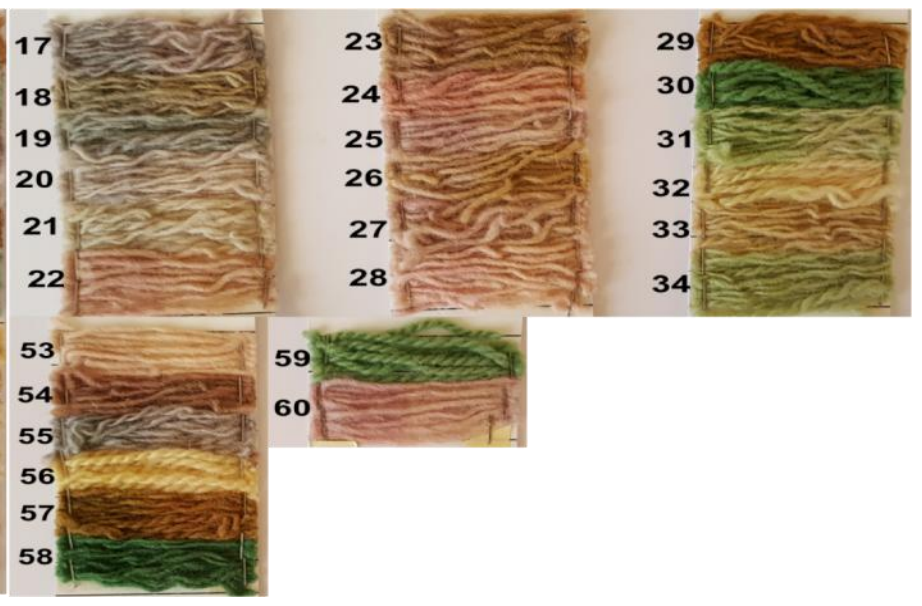

edilmektedir [18]. Boyar maddeler tekstil endüstrisi aritma tesislerinde tam olarak sudan uzaklaştırılamazlar, bu nedenle bu toksik bileşikler balıklar ve kabuklu canlılar gibi birçek sucul canlının bünyesinde depolanırlar ve sucul hayatı olumsuz yönde etkilerler. Bazı sentetik boyaların alerjenik oldukları da bilinmektedir. Günümüzde, doğal boyar maddelerin insan ve çevre sağlığına daha az toksik ve daha az alerjenik etkide olmasından dolayı kullanımı tekrar yaygınlaşmaya başlamıştır [19]. Bu alanda yapılan çalışmalar da ivme kazanmıştır.

Tutak ve Benli [20] yaptıkları çalıșmada, ayva kabuğu (Cydonia vulgaris), nar kabuğu (Punica granatum L.), kuru üzüm (Vitis vinifera L.), çay yaprağı (Camelia sinensis) ve elma yaprağı (Malus domestica)'nın boyar madde olarak kullanımı araștırmıșlardır. Mordan maddesi olarak ise Şap (KAI( $\left.\left(\mathrm{SO}_{4}\right)_{2} .12 \mathrm{H}_{2} \mathrm{O}\right)$, bakır sülfat $\left(\mathrm{CuSO}_{4} .5 \mathrm{H}_{2} \mathrm{O}\right)$ ve demir sülfat $\left(\mathrm{FeSO}_{4} .7 \mathrm{H}_{2} \mathrm{O}\right)^{\prime} 1$ çalışmalarında denemişlerdir. Boyama işlemlerinden sonra ışık haslığı, sürtme haslığı, yıkama haslığı ve ter haslığını belirlemişlerdir. Çalışmanın sonucunda ışık haslığında en yüksek verimin şap ve bakır sülfat mordanlarında, ter ve yıkama haslığında ise şap mordanında elde edildiği görülmüștür.

Aspir (Carthamus tinctorius) bitkisiyle yapılan bir diğer çalışmada [21], ışık haslık değerleri 2 ile 6 arasında bulunurken sürtünme haslık değerlerinin 12 ile 4-5 arasında olduğu belirlenmiștir. Işık haslığındaki en yüksek değerler mordan olarak bakırsülfat, demirsülfat ve potasyum bikromat ile elde ediliken sürtünme haslığında en düşük değer bakırsülfat ile mordanlamayla elde edilmiştir. Bakırsülfat ve potasyumkromatla mordanlama ișleminin sürtünme haslığında en yüksek değerleri veren mordan maddeleri olduğu belirtilmiștir.

Kılıçarslan [22], köknar kozalağını doğal boyar madde kaynağı olarak kullandığı çalışmasında, sürtünme haslığının mordanlama türüne bağlı olarak 4-5 arasında değiştiğini, en yüksek ışık haslık değerinin ise bakırsülfat ve demirsülfatla mordanlama yapılan ipliklerde olduğunu göstermiştir. 
Ölmez [23], fındık (Corylus avellana L.) bitkisi yaprağının yün halı iplikleri ile boyanırlığının araştırıldığı çalışmasında, ipliklerde elde ettiği renk ve haslık değerlerini belirlemiştir. Sonuç olarak ışık haslık değerlerinin 4-7 arasında, kuru sürtünme haslık değerlerinin 2-3 ile 5 arasında ve yaş sürtünme haslık değerlerinin 4-5 ile 5 arasında olduğunu göstermiştir.

$\mathrm{Bu}$ çalışmaların yanı sıra, Jothi [24] çuhaçiçeği (Tagetes erecta L.) bitkisi, Sarkar [25], kökboyası (Rubia tinctorum) ve çivit (Indigofera tinctoria) bitkileri, Kayabaşı ve Ölmez [26] elma yapraklarını, Kayabaşı ve Şanlı [27] soğan kabuklarını, Kayabașı ve Etikan [28] mürver (Sambucus Nigra) bitkisini, Öztürk ve Aksoy [29] kantaron (Hypericum triquetrifolium Turra.) bitkisini, Etikan [30] sergil (Plumbago eoropeae L.) bitkisini, Etikan ve ark. [31] kekik (Thymus sp.) bitkisini, Kılıç [32] nar (Punica granatum L) doğal boyar maddesi olarak kullanmış ve haslık değerlerini belirlemişlerdir.

Erkan ve Deniz [33], ebrako ağacının ektresini doğal kumaş boyası olarak kullandıkları çalışmalarında, mordan maddesi olarak, bakır (II) sülfat, potasyum bikromat, nikel (II) sülfat, demir (II) sülfat, potasyum alüminyum sülfat , gümüş nitrat maddelerini kullanmışlardır. Renk veriminin mordan maddesinin türüne göre değişiklik gösterdiğini ve en yüksek verimin gümüş nitrat mordanıla elde ettiklerini belirtmişlerdir.

Eser [34], kızılağaç yaprak eksteri ile yün ve pamuklu kumaşlarda mordanlı boyamalar gerçekleştiriştir. Demir sülfat ve potasyum alüminyum sülfat 1 mordanlama maddesi olarak kullandığı çalışmasında en iyi sonucu demir sülfat mordanı ile elde etmiştir. Ayrıca pH farklılıklarının da boyama üzerine etkilerinin araştırıldığı bu çalışmada bazik ortamın daha iyi sonuç verdiği gösterilmiştir.

$R$. tinctorium ekstresi ile yapılan ve potasyum dikromat, demir sülfat, bakır sülfat, kobalt klorür ve nikel klorürün mordanlama maddesi olarak kullanıldığı ve yün iplik boyamada kullanılabilirliğinin araştırıldığı bir çalışmada [35], potasyum dikromat, demir sülfat ve bakır sülfatın boyanan kumaşlar üzerinde daha iyi sonuç verdiği gösterilmiştir.

Nar kabuğunun doğal boyar madde olarak kullanıldığı bir diğer çalışmada [36] ise iyon sülfat farklı konsantrasyonlarda mordan maddesi olarak kullanılmıștır. Yün ipiliğin boyanma gücünün mordan konsantrasyonu ve ekstrakt miktarıyla büyük oranda orantılı olduğu belirtilmiștir.

Bahtiyari vd. [37] yaptıkları çalışmada, beş farklı (nar ve findık kabuğ u, portakal yaprăğ, havacıva kökü, papatya) bitkinin farklı kısımlarından pigment ekstraksiyonu yaparak doğal boyar madde olarak tekstildeki kullanımını araştırmıştır. Çevre dostu işlemler için mordan yerine binderin kullanıldığı çalışmada baskılı kumaşlarda yeterli haslık derecesini elde etmişlerdir.

Ceviz yaprağı ekstraktının asetik asit, sitrik asit, maleik asit, oksalik asit ve formic asit varlığında doğal boyar madde olarak araștırıldığı bir çalışmada [38] mordan maddesi olarak kalay klorür, potasyum alüminyum sülfat, demir sülfat ve bakır sülfat kimyasalları kullanılmıștır. Sitrik asit varlığında ve mordan maddesi olarak demir sülfatın kullanıldığı boyamanın en iyi sonucu verdiği belirtilmiștir.

Bitkilerin yüzyıllardır tekstilde boyar madde olarak kullanılırlığı bilinmektedir ve hala bu konudaki çalışmalar devam etmektedir. Ancak alglerin bu alandaki kullanımıyla ilgili yeterli sayıda çalıșma bulunmamaktadır. Yaptığımız bu çalışmada alglerin de bitkiler gibi iplik boyası olarak kullanılabilir olup olmadı $\breve{ı}$ araştırılmıştır. Bunu için mikroalglerden $C$. vulgaris, $P$. cruentum ve $H$. pluvialis ile makro alglerden $U$. lactuca ve G. gracilis türlerinden $\% 70$ etanol, \%60 metanol ve \%100 metanol kullanılarak pigment ekstaksiyonu gerçekleştirilmiştir. $\mathrm{Bu}$ ekstraktların her biri dört farklı kimyasal ile mordanlanmıștır. İplikler boyandıktan sonra ıșık haslıkları belirlenmiștir. Haslık dereceleri incelendiğinde en yüksek olarak $4 / 5$ haslık derecesinin elde edildiği görülmüştür. 60 örneğin 20 tanesi bu haslık derecesine sahiptir. $\mathrm{Bu} 20$ ipliğin ortak özelliği $\mathrm{CuSO}_{4}$ ya da $\mathrm{FeSO}_{4}$ ile mordanlanmıș olmalarıdır. En düşük haslık derecesi ise \%100 metanol ile $C$. vulgaris'ten yapılan yapılan pigment ekstraskiyonu ve ardından şap ile mordanlanarak gerçekleştirilen boyama sonucunda elde edilmiștir.

Haslık değeri başarısı türlere göre incelendiğinde en yüksek başarıyı $U$. lactuca ve $G$. gracilis makroalglerinden elde edilen pigmentlerle boyanan iplikler göstermiştir; haslık dereceleri 3 ile $4 / 5$ arasında değişmektedir. 3 ve üzeri haslık dereceleri tekstilde boya maddesi olarak kulanılabilecek kalitede olduklarını belirtmektedir. En düşük haslık sonucu ise $C$. vulgaris pigmenti ile yapilan boyamalarda elde edilmiştir. 12 örnekten 6'sı 3 ve üzeri sonuç vermiştir. İyi sonuç verenler ise $\mathrm{CuSO}_{4}$ ya da $\mathrm{FeSO}_{4}$ ile mordanlama yapılmıș olanlardır.

Tüm ipliklerde mordanlama ișlemi uygulanmıștır. mordanlama için en yaygın kullanılan mordanlama kimyasallarından $\mathrm{CuSO}_{4}, \mathrm{FeSO}_{4}, \mathrm{MgCl}_{2}$ ve şap kullanılmıștır. $\mathrm{CuSO}_{4}$ ve $\mathrm{FeSO}_{4}$ ile mordanlama yapılan tüm iplikler $3 / 4$ ve üzeri sonuçlar vermiștir. $\mathrm{MgCl}_{2}$ ile mordanlama yapılan 15 grubun 9 tanesi 3 ve üzeri haslık değeri gösterirken şap ile mordanlamada başarılı grup sayısı 8'e inmiștir.

Pigment ekstraksiyonundaki çözgenlerin etkisi karşılaştırıldığında ise önemli bir fark gözlenememiștir. Tüm alglerden $\% 70$ etanol, $\% 60$ 
metanol ve \%100 metanol ile pigment ekstraksiyonu yapılmıștır. $\mathrm{Bu}$ ekstraksiyon sonucu elde edilen pigmenler iplik boyamada kullanıldığında haslık derecelerinde çözgene bağlı bir fark oluşmadığı gözlenmiştir.

Elde edilen bu sonuçlar doğrultusunda denemelerde kullandığımız C. vulgaris, $H$. pluvialis, P. cruentum, $U$. lactuca ve $G$. gracilis türleri arasında iplik boyamada en etkili olan türlerin U. lactuca ve G. gracilis olduğu tespit edilmiștir. Bu türleri H. pluvialis ve P. cruentum mikroalg türleri izlemektedir. En iyi mordanlama ise $\mathrm{CuSO}_{4}, \mathrm{FeSO}_{4}$ kimyasalları ile gerçekleştirilmiştir. Pigment ekstraksiyonunun bu türlerden pigment eldesinde çok büyük bir fark oluşturmadığı gözlenmiştir. Mordan kullanılmadan yapılan boyamalarda en iyi sonucun U. lactuca ve G. gracilis türlerinden elde edilen ekstraktlar ve $H$. pluvialis türünün metanol ekstraklarından elde edildiği görülmüştür. Mordanlı boyama sonuçlarında da aynı türlerin en iyi sonucu verdiği gözlenmiştir.

U. lactuca Uzak Doğu mutfağında deniz marulu adı altında çeșitli yemeklerde kullanılmakta ve besin maddesi olarak tüketilmektedir. G. gracilis ise kırmızı alglerden elde edilen en önemli hammaddelerden biri olan agarın en çok elde edildiği ve bu nedenle Uzak Doğu'da deniz çiftliklerinde yüksek oranda üretildiği bilinen bir alg türüdür. G. gracilis ve U. lactuca kirliliğe daynıklı türlerdir ve Türkiye denizlerinde yaygın olarak bulunmaktadırlar.

Sonuç olarak, alglerin doğal iplik boyar maddesi olarak umut vadeden bir kaynak oluşturabileceği gözlenmiştir. İleride yapılacak olan çalışmalarda ışık haslığının yanı sıra yıkama haslı̆̆ı, kuru sürtünme haslığl, peroksit haslığl, alkali haslıklar gibi diğer haslık testleri ve renk ölçümleri de gerçekleştirilecektir. Bunun yanı sıra belirli dönemlerde oldukça fazla üreyen alg türleri ve Ülkemiz denizlerine sonradan girmiş olan istilacı alg türlerinin boyar madde olarak kullanılabilirliğinin araştırılması planlanmaktadır.

\section{Teşekkür}

$\mathrm{Bu}$ çalışma, Ege Üniversitesi Bilimsel Araştırma Projeleri tarafindan, 2014-FEN-051 numaralı proje ile desteklenmiştir. Işık haslığı analizlerini karşılıksız gerçekleștiren BoynerGrup'a katkılarından dolayı teşekkür ederiz.

\section{Kaynakça}

[1] Boyter, H. A. 2007. Environmental legislations USA. Christie R. M. ed. 2007. Environmental aspects of textile dyeing. Woodhead, Cambridge, England, 235s.

[2] Singh K., Arora S., 2011. Removal of synthetic textile dyes from wastewaters: a critical review on present treatment technologies. Critical
Reviews in Environmental Science and Technology, 41(2011), 807-878.

[3] Eren H. A., Aniş P. 2006. Tekstil boyama atıksularının ozonlaama ile renk giderimi. Uludağ Üniversitesi Mühendislik-Mimarlık Fakültesi Dergisi, 11(2006), 83-91.

[4] Hutchings, M. G., Ebenezer, W. J. 2000. Super Efficient Dyes for the Coloration of Cotton: The Procion XL+ Range, www.chemsoc.org. (Erişim tarihi 16.09.2017)

[5] Easton, J. R. 1995. The problem of colour. ss 921. Cooper P. ed. Color in dye house effluent. Society of Dyers and Colourists, Bradford, England, 88s.

[6] De Aragao, U. G., Freeman, H. S., Warren, S. H., de Oliveira, D. P., Terao, Y., Watanabe, T., and Claxtons, L. D. 2005. The contribution of azo dyes to the mutagenic activity of the Cristais River. Chemosphere 60(2005), 55-64.

[7] Chu, W. 2012. Biotechnological applications of microalgae. E-Journal - International Medical University 6/1(2012), 24-37.

[8] Sumanta N., Haque C. I., Nishika J., Supraskash R. 2014. Spectrophotometric Analysis of Chlorophylls and Carotenoids from Commonly Grown Fern Species by Using Various Extracting Solvents. Research Journal of Chemical Sciences. 4/9(2014), 63-69.

[9] Torres, B. P., Chow F., Furlan, M. C., Mandelli, F., Mercadante, A., Santos, D. Y. A. C. 2014. Standardization of a Protocol to extract and analyze chlorophyll a and carotenoids in Gracilaria tenuistipitata var. Liui. Zhang and Xia (Rhodophyta). Brazilian Journal of Oceanography. 62/1(2014), 57-63.

[10] Dere, Ş., Güneş, T., Sıvacl, R. 1998. Spectrophotometric Determination of Chlorophyll - A, B and Total Carotenoid Contents of Some Algae Species Using Different Solvents. Turkish Journal of Botany, 22(1998), 13-17.

[11] Bechtold, T., Turcanu, A., Ganglberger, E., Geissler S. 2002. Natural dyes in modern textile dyehouses - how to combine experiences of two centuries to meet the demands of the future? Journal of Cleaner Production, 11(2003), 499-509.

[12] Colombini, M. P., Andreotti, A., Baraldi, C., Degano, I., Lucejko, J. J. 2007. Colour fading in textiles: A model study on the decomposition of natural dyes. Microchemical Journal, 85(2007), 174-182.

[13] Bidigare, R. R., Odrusek E. 1990. In vivo absorbtion proporties of algal pigments. Proceedings of The International Society for Optical Engineering, 1320 (1990), 290-302.

[14] Priyadershani, I., Rath, B. 2012. Commercial and Industrial applications o micro algae- A riview. 
Journal of Algal Biomass and Utilization, 3/4 (2012), 89-100.

[15] Taylor, G.W. 1986. Natural dyes in textile applications. Review of Progress in Coloration, 16(1986), 53-61.

[16] Şen, S., Demirer, G.N. 2003. Anaerobic treatment of real textile wastewater with a fluidized bedreactor. Water Research, 37(2003), 18681878.

[17] Şahin, N., Türkoğlu, Ş. 2014. Bazı Tekstil Boyalarının Drosophila melanogaster'de Ömür Uzunluğu, Yaşama Yüzdesi ve Yavru Birey Sayısına Etkileri. Cumhuriyet Üniversitesi Fen Bilimleri Dergisi, 35/4(2014), 1-21.

[18] Eren, H. A., Kurcan, P., Aniş, P. 2007. Boyamada kullanılan yardımcı kimyasal maddelerin reaktif boyama atık sularının ozonlanmasına etkileri. Uludağ Üniversitesi Mühendislik-Mimarlık Fakültesi Dergisi, 12/2(2007), 53-60.

[19] Deveoğlu, O., Karadağ, R. 2011. Genel bir bakış: Doğal boyar maddeler. Marmara Üniversitesi Fen Bilimleri Dergisi, 23/1(2011), 21-32.Ali, S., Nisar, N., Hussain, T. 2007. Dyeing properties of natural dyes extracted from eucalyptus. The Journal of Textile Institute, 98/6(2007), 559562.

[20] Tutak, M., Benli, H. 2008. Bazı bitkilerden elde edilen doğal boyar maddelerin yünü boyama özelliğinin incelenmesi . Balıkesir Üniversitesi Fen Bilimleri Dergisi, 10/2(2008), 53-59.

[21] Kayabaşı, N., 1998. Aspir (Carthamus tinctorius) çiceklerinden elde edilen renklerin ışık ve sürtünme has llk değerleri . Ankara Üniversitesi Ziraat Fakültesi Tarım Bilimleri Dergisi, 4/1(1998), 56-62.

[22] Kılıçarslan, H. 2006. Köknar (Abies) kozalaklarından elde edilen renkler ve bu renklerin yün hali iplikleri üzerindeki haslık değerleri. Ankara Üniversitesi Fen Bilimleri Enstitüsü, Yüksek Lisans Tezi, 70s, Isparta.

[23] Ölmez, F. N., 2005. Yün Halı ipliklerinin Fındık (Corylus avellana L.) Yaprakları ile Boyanmasından Elde Edilen Renkler ve Bazı Haslık Değerleri. Yüzüncü Yll Üniversitesi, Ziraat Fakültesi, Tarım Bilimleri Dergisi, 15/1(2005), 77-84.

[24] Jothi, D. 2008. Extraction Of Natural Dyes From African Marigold Flower (Tagetes Ereecta L.) For Textile Coloration. AUTEX Research Journal, 8(2008): 49-53.

[25] Sarkar, A.J. 2004. An evaluation of UV protection imparted by cotton fabrics dyed with natural colorants. BMC Detmatology 4(2004),15-17.

[26] Kayabașı, N., Ölmez, F., 2000. Elma yapraklarından elde edilen renkler ve bu renklerin bazı haslık değerleri üzerinde bir araştırma. Ankara Üniversitesi Ziraat Fakültesi
Tarım Bilimleri Dergisi, 2(2008), 16-20.

[27] Kayabaşı, N., Şanlı, H.,S. 2000. Soğan kabuklarının bitkisel boyacılıkta kullanımı. Türk-Koop Ekin Dergisi, 14(2000), 99-103.

[28] Kayabasi, N., Etikan, S., 1998. Mürver (Sambucus Nigra L.). bitkisinden elde edilen renkler ve bu renklerin yun halı iplikleri üzerindeki ışık ve sürtünme haslıkları . Ankara Üniversitesi Ziraat Fakültesi Tarım Bilimleri Dergisi, 4-3(1998), 6569.

[29] Öztürk, I., Aksoy, A., 2000. Kantaron (Hypericum triquetrifolium Turra.) bitkisinden elde edilen renkler ve bu renklerin yün halı iplikleri üzerindeki ışık ve yıkama haslıkları . Ankara Üniversitesi Ziraat Fakültesi Tarım Bilimleri Dergisi, 6(2000), 110-115.

[30] Etikan, S., 1996. Sergil (Plumbago europeae L.)'den Elde Edilen Renkler ve Bu Renklerin Yün Hali iplikleri üzerindeki Işık ve Sürtünme Haslıkları. Ankara Üniversitesi , Fen Bilimleri Enstitüsü Yüksek Lisans Tezi, 42s Ankara.

[31] Etikan, S., Kayabasi, N., Kızıl, S., 2000. Kekik (Thymus sp.) bitkisinden elde edilen renkler ve bu renklerin bazı hasliklari üzerinde bir arastirma. Ankara Üniversitesi Ziraat Fakültesi Tarım Bilimleri Dergisi, 6(2000), 35-37.

[32] Kılıç, B., 1994. Nar (Punica granatum L.) Meyve Kabuğundan Elde Edilen Renkler ve Bu Renklerin Yün Halı iplikleri Üzerindeki Işık ve Sürtünme Haslıkları . Ankara Üniversitesi Fen Bilimleri Enstitüsu , Yüksek Lisans Tezi ，50s, Ankara.

[33] Erkan, G., Deniz, S., 2017. Yünlü kumaşların Kabeko ekstresi kullanılarak basılması. TMMOB Tekstil Mühendisleri Odası, 103 (23), 205-212.

[34] Eser, F., 2016. Kızılağaç yapraklarının tekstil endüstrisinde boyar madde kaynağ değerlendirilmesi. Anadolu Üniversitesi Bilim ve Teknoloji Dergisi A-Uygulamalı Bilimler ve Mühendislik, 17(1), 199-2017.

[35] Feiz, M., Norouzi, H., 2014. Dyeing studies of wool fibers with madder (Rubia tinctorium) and effect of different mordants and mordanting procedures on color characteristics of dyed samples. Fibers and Polymers, 15, 2504-2514.

[36] Tutak, M., Acar, G., Akman, 0. 2014. Natural dyeing properties of wool fabrics by pomegranate (Punica granatum) peel. Tekstil ve Konfeksiyon, 24, 81-85.

[37] Bahtiyari, M. İ., Benli, H., Yavaş, A., Akca, C., 2017. Use of Different natural dye sources for printing of cotton fabrics. Tekstil ve Konfeksiyon, 27(3), 259-265.

[38] Eser F, Sanal S, Temiz C, Yilmaz F, Onal A. Effect of acid pretreatment on the dyeing performance of walnut (Juglans regia) leaves on wool fibers. Fiber Polym 2015; 16: 1657-1662. 